\title{
Sigilo, anonimato e confidencialidade de doadores de sangue com HIV
}

Newton Key Hokama ${ }^{1}$, Pedro Bonequini Junior ${ }^{2}$, Paula de Oliveira Montandon Hokama ${ }^{1}$

1. Universidade Estadual Paulista "Júlio de Mesquita Filho", Botucatu/SP, Brasil.

2. Hospital das Clínicas da Faculdade de Medicina de Botucatu, Unesp, Botucatu/SP, Brasil.

\section{Resumo}

Na ocorrência de resultado positivo para HIV em triagem sorológica para doação, o serviço de hemoterapia deve, além de descartar a bolsa de sangue, encaminhar o doador ao serviço de referência. A situação, no entanto, traz dilemas éticos implícitos, vivenciados cotidianamente pelos profissionais da área. Assim, o objetivo do presente estudo é revisar pormenorizadamente a legislação sobre o assunto, desenvolvendo reflexões necessárias. Tendo em vista que a condição de ser portador de HIV/aids está envolta em preconceitos, discriminações e repercussões sociais negativas, é fundamental que o profissional da hemoterapia responsável por comunicar a inaptidão esteja ciente do sigilo e da confidencialidade das informações e devidamente capacitado para atuar nessa situação. $\mathrm{O}$ artigo defende a comunicação plena da inaptidão sorológica ao doador.

Palavras-chave: Soroprevalência de HIV. Doadores de sangue. Confidencialidade.

\section{Resumen}

Secreto, anonimato y confidencialidad de los donantes de sangre con VIH

En caso de resultado positivo para VIH en cribado serológico para donación, el servicio de hemoterapia debe desechar la bolsa de sangre y remeter el donante a un servicio de salud de referencia. Esta situación, sin embargo, conlleva dilemas éticos implícitos que los profesionales del ramo enfrentan cada día. Así, el objetivo de este estudio es revisar en detalle la legislación sobre la materia, desarroIlando reflexiones necesarias. Tengo en cuenta que la condición de ser portador de $\mathrm{VIH} / \mathrm{sida}$ conlleva prejuicios, discriminación y repercusiones sociales negativas, es fundamental que el profesional de hemoterapia encargado de comunicar la inaptitud sea consciente del secreto y de la confidencialidad de la información y también debidamente capacitado para actuar en esta situación. Este artículo defiende la plena comunicación de inaptitud serológica al donante.

Palabras-clave: Seroprevalencia de VIH. Donantes de sangre. Confidencialidad.

\section{Abstract}

\section{Secrecy, anonymity and confidentiality in blood donors with HIV}

A recent article published in this journal on confidentiality in the care of HIV/aids patients reports that, in the event of a positive result in the Screening Tests for the virus, the Blood Bank must, in addition to disposing of the blood bag, refer the donor to the reference service. Due to the implicit ethical dilemmas we have experienced, this led us to a detailed review of the respective brazilian legislation and critical analysis of the issue. People with HIV/aids are surrounded by prejudices, discrimination and negative social repercussions, so it is essential that the Blood Bank professional who will communicate this news is fully aware of the issues involving secrecy and confidentiality, and fully trained and capable to proceed adequately. We present and discuss the fundamental points of the current Brazilian legislation the theme and how we must communicate to the donor about the detection of HIV serodiagnosis.

Keywords: HIV seroprevalence. Blood donors. Confidentiality. 


\section{Breve história da aids}

Os profissionais da saúde em atividade testemunharam in loco os significativos avanços na identificação, diagnóstico e tratamento da aids desde o surgimento dos primeiros casos nos anos $1980^{1}$. Inicialmente, acreditava-se que a doença afetava apenas homens homossexuais ${ }^{2}$, mas os mesmos eventos clínicos começaram a ser observados em usuários de drogas injetáveis, pacientes hemofílicos e homens e mulheres heterossexuais. Foi ficando evidente que tais eventos decorriam de uma imunodeficiência adquirida, que foi denominada "acquired immunodeficiency syndrome" (aids) - a "síndrome da imunodeficiência humana", em português.

A identificação do human immunodeficiency virus (HIV), ou vírus da imunodeficiência humana, como agente causador da aids, noticiada em maio de $1983^{3}$, desencadeou uma sequência de conquistas tecnológicas e científicas que alavancaram o desenvolvimento de toda a medicina. Desde então assistimos tanto à disseminação epidêmica da doença como a sucessivas conquistas terapêuticas, iniciada com a azidotimidina (AZT), passando pelos coquetéis, e chegando à carga viral indetectável como alvo terapêutico, com o atual e bem mais simplificado esquema antirretroviral. Apesar disso, e mesmo sendo o Brasil um dos países cujo sistema de saúde público fornece todas as medicações necessárias e acompanhamento clínico e laboratorial, o estigma de ser portador do HIV permanece.

\section{Aids e a legislação sobre atividade hemoterápica no Brasil}

Um efeito direto do aparecimento da aids foi acelerar a reestruturação dos serviços de hemoterapia no Brasil por meio do Programa Nacional de Sangue e Hemoderivados, criado em 1980 pelo Governo Federal, mas cuja efetividade somente se fez sentir após a pressão popular gerada pelo surgimento de casos de aids transfusional ${ }^{4}$.

Os exames sorológicos para detectar o HIV em doadores de sangue foram implantados em 1985 nos hemocentros, mas só a partir de 1988 se tornaram obrigatórios para todo o território brasileiro ${ }^{5}$, inclusive para os serviços privados de hemoterapia, por meio da Lei Federal 7.649/1988 ${ }^{6}$. Essa lei, que visava prevenir a propagação de doenças pela transfusão, estabeleceu a obrigatoriedade de cadastramento dos doadores de sangue, incluindo registro de documento de identidade, tornando a doação de sangue um ato de responsabilidade civil.

No mesmo ano de 1988 foi promulgada a Constituição brasileira ${ }^{7}$, que em seu artigo 199 , parágrafo 4, vedou todo tipo de comercialização na coleta, processamento e transfusão de sangue e seus derivados. Esse parágrafo foi regulamentado pela Lei $10.205 / 2001^{8}$, que estabeleceu o ordenamento institucional da atividade hemoterápica no país. A Lei, no item VII do artigo $3^{\circ}$, ao se referir sobre os cuidados ao doador de sangue, determina que proteger e orientar o candidato a doador inapto inclui encaminhá-lo a unidades que promovam reabilitação ou suporte clínico, terapêutico e laboratorial necessários ao seu bem-estar físico e emocional. No artigo 14, que se refere a princípios e diretrizes da Política Nacional de Sangue, garante-se, entre outros, o direito ao sigilo dos resultados e à informação do candidato a doador sobre qualquer anomalia identificada nos testes laboratoriais e sobre procedimentos que se seguirão.

A Portaria de Consolidação 5/2017, do Ministério da Saúde ${ }^{9}$, redefiniu o regulamento técnico dos procedimentos hemoterápicos então vigentes, tendo como base a Resolução 34/2014 da Agência Nacional de Vigilância Sanitária ${ }^{10}$. Essa portaria é a fonte jurídica última que regula os temas abordados no presente estudo: o doador e os procedimentos de doação de sangue e como lidar com a inaptidão sorológica, em especial no exame positivo para HIV. O artigo 30 estabelece que a doação de sangue deve ser voluntária, anônima e altruísta, e o artigo 31 garante que $o$ sigilo das informações prestadas pelos doadores antes, durante e depois do processo de doação deve ser absolutamente preservado, respeitadas outras determinações previstas na legislação vigente.

De acordo com a mesma portaria ${ }^{9}$, para detectar a presença do HIV nos doadores, são obrigatórios testes sorológicos (que detectam anticorpos ou complexo antígeno-anticorpo) e moleculares (que, pela tecnologia do ácido nucleico, detectam diretamente a presença do vírus). A presença de resultado positivo ou inconclusivo após repetição dos testes em duplicata na mesma amostra implicará a convocação do doador para coleta de novas amostras ou orientação, conforme o artigo 129, 
que trata da obrigatoriedade de exames laboratoriais em toda doação para identificar doenças infecciosas transmissíveis pelo sangue ${ }^{9}$.

O artigo 32 da Portaria $5 / 2017^{9}$ determina que o doador deve assinar termo de consentimento livre e esclarecido em que autoriza a realização dos testes de laboratório exigidos pelas leis e normas técnicas vigentes. O mesmo artigo prevê que, em caso de resultados reagentes ou inconclusivos, os serviços de hemoterapia e órgão de vigilância em saúde estão autorizados a empreender "busca ativa" para repetir testes. Nesse sentido, o artigo 68 da portaria prevê que o serviço de hemoterapia deve informar mensalmente à autoridade sanitária competente os dados dos doadores, com resultados dos testes laboratoriais para doenças transmissíveis pelo sangue, reagentes nas repetições em duplicata e ausência dos convocados para coletar novas amostras ou receber orientações ${ }^{9}$. Em complementaridade à portaria, conforme o artigo $99 \mathrm{da}$ já citada Resolução $34 / 2012^{10}$, o retorno do doador considerado inapto ao serviço de hemoterapia visa o esclarecimento, a repetição dos testes e o encaminhamento a serviços de saúde de referência.

\section{Doador de sangue e triagem clínica e sorológica para HIV}

Em artigo recente, Salvadori e Hahn ${ }^{11}$ apresentaram resultados de ampla revisão integrativa de literatura sobre o tema da confidencialidade médica no cuidado de pacientes com HIV/aids. Os aspectos da hemoterapia abordados pelas autoras - notadamente a comunicação ao doador sobre a inaptidão sorológica pelo HIV - nos incentivaram a reflexão que resultou no presente artigo. $O$ objetivo é aprofundar esse ponto, sobretudo no que se refere à legislação e seu reflexo nas ações profissionais.

Como já destacado, a hemoterapia deve muito de seu estado atual aos avanços tecnológicos decorrentes do estudo da aids. Devido ao papel estratégico da transfusão na terapia médica, era fundamental assegurar a segurança quanto à não transmissão de aids e outras doenças infecciosas por meio do procedimento. Havia, portanto, um desafio: como garantir a segurança da transfusão se essa é uma das principais vias de transmissão da aids?

Mesmo com os avanços dos métodos laboratoriais, a triagem clínica dos doadores continua sendo uma das principais medidas de segurança transfusional. A triagem inclui a aplicação de um questionário que aborda o histórico do doador, inclusive seu comportamento sexual. Esse questionário é padronizado de acordo com manuais de procedimentos operacionais cuja existência é determinada pelo artigo 237 da Portaria de Consolidação 5/20179.

A depender do teor das respostas ao questionário de triagem clínica, o entrevistador pode recusar a doação, conforme previsto no artigo 67 da Portaria de Consolidação $5 / 2017^{9}$. Nesse caso, o profissional deve informar o motivo da inaptidão, que pode ser temporária ou definitiva. Tendo em vista que o doador procura altruística e voluntariamente o serviço de hemoterapia, a recusa pode ser uma fonte de frustação, por isso a decisão deve ser comunicada de modo adequado, com as devidas justificativas.

Há uma segunda estratégia que visa aumentar a segurança da triagem clínica: o voto de autoexclusão ${ }^{12}$. Caso o entrevistado, por se sentir constrangido com as perguntas, tenha omitido informações relevantes, no final da doação ele pode assinalar, por preenchimento eletrônico ou manual, sem qualquer intermediação humana, que considera a doação inadequada para transfusão, impedindo o uso da bolsa pelo serviço de hemoterapia.

Mesmo com todos os cuidados citados, a inaptidão sorológica nos testes (resultado positivo ou duvidoso de um ou mais testes para o HIV) é factível. Nessa situação, os serviços de hemoterapia devem proceder de acordo com a legislação ${ }^{10}$. O doador será convocado, comunicado sobre a causa da inaptidão e submetido a coleta de nova amostra para confirmar ou não a presença de HIV. Nessa comunicação, o paciente deve ser informado de que a doação não se completou (a bolsa foi descartada), ser encaminhado ao SUS para tratamento com antirretrovirais (se confirmada a positividade) e receber orientações sobre riscos de transmissão via relação sexual, gestação e futuras doações de sangue.

\section{Sigilo e confidencialidade}

Os seres humanos se comunicam, presencial ou virtualmente, independentemente de distância, tempo e palavras: a comunicação é inerente à 
condição humana ${ }^{13}$. Pela comunicação, obtemos informações verbais e não verbais, algumas das quais devem ser conhecidas apenas pelos participantes do diálogo. Trata-se de informações sigilosas ou, como denominadas pelo senso comum, "segredos".

No entanto, como seres comunicantes, guardar segredo não parece natural para nós. Assim, mecanismos comportamentais, legais e éticos são necessários para resguardar informações que não devem ser divulgadas. Relações profissionais são baseadas em primeiro lugar na comunicação, e as informações que dela decorrem são, em princípio, sigilosas. O sigilo profissional ${ }^{14}$, isto é, que envolve informações do assistente sobre o assistido (por exemplo, o médico e o paciente), é eticamente complexo e não se limita a um único preceito, tendo em vista que são várias as situações e dilemas que ameaçam sua preservação.

A atenção na saúde não se resume à relação entre assistente e assistido - médico e paciente, ou médico e doador -, mas envolve outras dimensões. É preciso considerar que as informações obtidas são compartilhadas institucionalmente (no prontuário médico, em sistemas de registro epidemiológico etc.) e socialmente (boletins médicos de pessoas ilustres em tratamento hospitalar, por exemplo). Por consequência, o conceito do sigilo profissional deve ser compreendido de forma que abranja essas dimensões.

O sigilo profissional na saúde já era abordado no Juramento de Hipócrates, até hoje utilizado na cerimônia de colação de grau da maioria dos cursos de medicina: Aquilo que no exercício ou fora do exercício da profissão e no convívio da sociedade, eu tiver visto ou ouvido, que não seja preciso divulgar, eu conservarei inteiramente secreto ${ }^{15}$. O respeito ao sigilo também é um dos princípios fundamentais do Código de Ética Médica, salvo exceções previstas em lei ${ }^{16}$. Nessas duas formulações exige-se do profissional capacidade de julgar o que deve ou não ser divulgado, isto é, o sigilo não é absoluto, depende de circunstâncias, e portanto é uma questão ética.

O elemento decisivo na relação entre assistente e assistido é a confiança mútua, que torna possível o diálogo e o entendimento. O sigilo é uma premissa para que essa confiança se desenvolva. No entanto, como dependente das circunstâncias, nem sempre o pacto de sigilo é explícito ou formalizado. Um bom exemplo é o treinamento prático de futuros profissionais de saúde, que envolve muitas situações complexas de sigilo profissional. Estudantes e residentes, ao finalizar o atendimento, informam ao paciente que vão se encontrar com preceptores e professores para analisar o caso (checagem). Nessa situação, a relação inclui, além do paciente e do estudante/ residente, o professor/preceptor.

Da mesma forma, as informações do prontuário, apesar de pertencentes ao paciente, estarão à disposição de outros profissionais que têm permissão institucional para acessá-las (e é provável que a maioria dos pacientes desconheça esse fato). A apresentação de pacientes em visitas de enfermaria ou discussão de casos também é um momento em que se compartilham dados clínicos. $\mathrm{E}$ fora do ambiente acadêmico, quando se solicita avaliação a outro profissional, a carta de encaminhamento, devidamente protegida da leitura por terceiros, também contém dados clínicos.

As situações citadas mostram que a extensão do sigilo a terceiros é consequência da necessidade de opinião ou ação de outros profissionais. Atividades exclusivamente didáticas também são situações em que se divulgam dados clínicos. Porém, nessas atividades, é altamente recomendável que se utilizem pseudônimos, siglas ou apenas o primeiro nome do paciente, preservando o anonimato. No ambiente de treinamento profissional, o sigilo deve ser constantemente ensinado, citado, lembrado e preservado, como forma de educação contínua de alunos, residentes e profissionais.

Em publicações científicas, por serem de acesso público, mesmo que se utilize obrigatoriamente o anonimato ou pseudônimo, o sigilo profissional ainda pode ser violado. Assim, para publicar os dados, é imprescindível, exceto em caso de definitiva impossibilidade, obter autorização do paciente ou responsável legal mediante assinatura de termo de consentimento livre e esclarecido. Em síntese, o sigilo profissional, por ser pactuado (implícita ou formalmente), é indissociável das relações profissionais, e deve-se preservá-lo ao máximo, no limite das circunstâncias.

Ao se assumir que a manutenção do sigilo é objeto de julgamento por parte do profissional, tendo em vista a possibilidade de violação diante de situações extraordinárias, torna-se clara a necessidade de preceitos éticos. Com relação ao diagnóstico de HIV/aids, há alguns pressupostos: 
a manutenção do sigilo pode ameaçar diretamente a integridade física de outras pessoas, pelo risco de se infectarem caso tenham relações sexuais ou compartilhem seringas (no caso de usuários de drogas ilícitas injetáveis) com o paciente.

Nesse caso, segue-se o princípio do mal menor, apontado pelo Conselho Federal de Medicina (CFM) já nos primeiros anos da aids como motivo para violar o sigilo do paciente infectado ${ }^{17}$. Assim, aceita-se que o parceiro sexual de um indivíduo infectado pelo HIV seja informado desse fato desde que o paciente, tendo sido adequadamente alertado quanto ao risco de contaminação, recuse-se a comunicar o diagnóstico para pessoas potencialmente infectadas ${ }^{18}$.

Nesse ponto, é necessário distinguir os conceitos de sigilo e de confidencialidade. O sigilo profissional, restrito aos envolvidos, refere-se a informações obtidas em relações interpessoais e em documentos concernentes a essas relações. Sua natureza, portanto, é relacional, intersubjetiva. Trata-se de um pacto construído entre pessoas e grupos ou instituições, e que é produto das circunstâncias. Já a confidencialidade se refere a sistemas de dados ou de informação. Como definida pela Associação Brasileira de Normas Técnicas na norma ISSO/IEC 17799:2005, a confidencialidade é a garantia de que a informação seja acessível apenas a pessoas e instituições autorizadas ${ }^{19}$. Sua natureza, portanto, é objetiva, o que a torna passível de ser plenamente regulamentada. Institucional e social, a confidencialidade é resultado de planejamento, legislação e constante monitoramento e vigilância.

O sigilo é regulado, regulamentado, regimentado pela confidencialidade. Sendo um pacto, ele depende de uma derradeira decisão: preservá-lo ou não. Quando se decide pela quebra do sigilo, o passo seguinte é decidir quem mais terá acesso às informações, e se isso exigirá repactuações, e assim por diante, numa sequência de decisões e acordos. Portanto, o sigilo profissional é sempre uma decisão ética. A confidencialidade, diferentemente, contém um conjunto predeterminado de regras que zela para que o acesso à informação esteja disponível apenas para quem de direito. Pode-se concluir que a confidencialidade é de natureza institucional, enquanto o sigilo está no âmbito das relações pessoais - a primeira é objetiva (a partir da informação), e a segunda é subjetiva (a partir dos sujeitos envolvidos).
Como exemplo, pode-se abordar a mesma informação em diferentes contextos institucionais. Um homem, sendo sabidamente portador do HIV, mantém relações sexuais com seu(sua) companheiro(a) - a quem não comunicou o resultado dos exames - sem a devida proteção (uso de preservativos). Estão cientes desse fato tanto o médico da Unidade Básica de Saúde (responsável pelo diagnóstico) e o sacerdote da paróquia (por confissão). Ambos estão diante de sigilo, mas o profissional da saúde já deu o ultimato: caso o paciente não conte para o(a) companheiro(a) em 24 horas que é soropositivo, o fato será comunicado à revelia, com o amparo do Código de Ética Médica e das leis que instituíram o Código Sanitário (Vigilância Epidemiológica e Sanitária). O padre, porém, está impedido de revelar o fato pelo inviolável sigilo da confissão ${ }^{20}$. Assim, embora a informação seja sigilosa tanto para o padre como para o médico, as confidencialidades - e portanto as atitudes - são distintas.

\section{Confidencialidade da doação de} sangue

A doação de sangue deve ser voluntária, anônima e altruísta ${ }^{10}$. No entanto, o doador não é anônimo, já que deve apresentar documento de identidade ao se apresentar como candidato e é chamado pelo nome durante toda a permanência no ambiente da doação. Quem recebe a transfusão também não é anônimo, pois ser identificado e tratado por nome e sobrenome em serviços médicos é um direito do paciente ${ }^{21}$. O anonimato só é um conceito possível pelo fato de que, a partir da coleta do sangue, as bolsas coletadas e os tubos de exames são identificados com numeração ou código de barras. Todo o processo de separação, armazenamento, exames e liberação das bolsas é realizado com essa identificação codificada e sigilosa. Não há qualquer possibilidade de que paciente ou funcionários identifiquem o doador por meio dos tubos de exames e as bolsas de sangue.

Se o paciente se sentir motivado a retribuir o doador (com agradecimento ou entrega de presentes), isso não será possível, assim como não se permite ao doador conhecer a identidade do receptor. Se, por livre iniciativa, o doador ou o paciente decidem publicar imagem doando ou recebendo a transfusão em redes sociais, não há quebra de 
sigilo. O que ocorre nesse caso é a divulgação do ato de doar ou de receber transfusão. $O$ anonimato, portanto, está associado ao processo de doação de sangue, e não ao ato de doar ou de receber transfusão. A codificação dos tubos de exames e as bolsas de sangue são os mecanismos de proteção para que as informações permaneçam sigilosas.

No momento de aprovação na triagem clínica, todo candidato a doador de sangue deve assinar, após ser informado sobre todo o conteúdo do documento, um termo de consentimento livre e esclarecido (artigo 32 da Portaria de Consolidação 5/2017) ${ }^{9}$ no qual declara expressamente consentir a realização de todos os testes de laboratório exigidos pelas leis e normas técnicas vigentes. Por meio do termo o candidato também aceita que seu nome seja incorporado ao arquivo de doadores local e nacional, e que em caso de resultados reagentes ou inconclusivos nas triagens laboratoriais, ou em situações de retrovigilância, seja permitido ao serviço de hemoterapia ou órgão de vigilância convocá-lo ou empreender busca ativa para repetir testes. Dessa forma, ao ser convocado, não há como o candidato a doador evitar a comunicação sobre o motivo da inaptidão sorológica, isto é, a presença do HIV, ou negá-la, nos casos duvidosos. Tendo em vista a possibilidade de encaminhamento para outros serviços para início do tratamento com antirretrovirais e os riscos de contaminação por via sexual, gestacional ou amamentação, não seria aceitável qualquer omissão ao informar o resultado dos exames.

Uma vez detectado o HIV ou outro agente infeccioso em um doador, é necessário levantar suas possíveis doações anteriores. Toda doação de sangue, portanto, está sujeita a ser revista retrospectivamente, se necessário. Esse conceito computacional, denominado "rastreabilidade" ${ }^{22}$, garante que se possa identificar, em determinadas circunstâncias previstas na legislação, a partir da quebra de sigilo da identidade do doador, os respectivos hemocomponentes e seus receptores. A rastreabilidade tem mão dupla, ou seja, a partir de um receptor que suspeita ter adquirido aids ou outra doença por via transfusional também se pode identificar os hemocomponentes recebidos e seus doadores. Dessa forma, ao se rever o percurso dos hemocomponentes nas situações previstas, doadores e pacientes poderão ser convocados para coleta de amostras de sangue e para comunicação de resultados da retrovigilância.
A confidencialidade da doação de sangue, embora não seja nomeada dessa forma, pode ser compreendida por meio de leis e normas técnicas vigentes que regulam o sigilo profissional nas várias etapas do processo: triagem clínica (entrevista, assinatura do termo de consentimento livre e esclarecido, voto de autoexclusão), inaptidão sorológica (convocação do doador, comunicação da causa da inaptidão, coleta de novas amostras e encaminhamento para serviço de referência para confirmação ou tratamento) e rastreabilidade. A confidencialidade, pressuposto fundamental e inquebrantável na doação de sangue, garante que apenas os profissionais diretamente envolvidos com o doador inapto poderão conhecer sua identidade.

Estudo com doadores de sangue com sorologia reagente para sífilis, hepatites virais e HIV mostrou que cerca de $40 \%$ assumiram ter omitido informações na triagem clínica. A possibilidade de autoexclusão no final da doação também não foi considerada pela maioria absoluta dos doadores $(98,1 \%)^{23}$. A soropositividade para HIV foi detectada em 0,03\% das doações. Esses resultados apontam que, além da triagem clínica, do voto de autoexclusão e da triagem sorológica, a estratégia mais importante para diminuir o risco de transmissão de doenças infecciosas por via transfusional ainda é e sempre será a conscientização e educação da população. Não haverá transfusão absolutamente segura sem a consciência de que se trata de um ato de cidadania e amor.

\section{Considerações finais}

O estigma do HIV/aids é real, debilitante, e resiste até hoje, quando já se sabe que não há "grupos de risco" (a chance de se infectar independe de idade, gênero, orientação sexual ou grau de escolaridade) e o SUS oferece tratamento efetivo para a doença.

No que se refere à doação de sangue, procedimentos como triagem clínica e sorológica e voto de autoexclusão são fundamentais para diminuir os riscos de transmissão de doenças. Leis e normas técnicas determinam como os serviços de hemoterapia devem realizar esses procedimentos. Doadores com exame positivo ou duvidoso para HIV são convocados e comunicados do resultado, submetem-se a nova coleta de sangue para repetição dos exames e recebem orientações e encaminhamentos. 
A confidencialidade é um fundamento ético da área da saúde que zela pela preservação da integridade da pessoa, com especial atenção para pacientes com HIV ou aids, pelo estigma social da doença. O sigilo profissional é um pacto construído nas relações entre assistente e assistido, baseado em preceitos éticos e legais e regido pela confidencialidade. Nesse sentido, a inaptidão em decorrência de soropositividade deve ser comunicada ao doador com total respeito, precisão e clareza. Apesar de todos os avanços técnicos e tecnológicos na triagem, os esforços de educar e conscientizar a população ainda são fundamentais tanto para diminuir a transmissibilidade do HIV via transfusão como para combater o preconceito social que cerca os portadores desse vírus.

\section{Referências}

1. Greene WC. A history of AIDS: looking back to see ahead. Eur J Immunol [Internet]. 2007 [acesso 10 fev 2021];37:94-102. DOI: 10.1002/eji.200737441

2. Centers for Disease Control. Kaposi's sarcoma and Pneumocystis pneumonia among homosexual men: New York City and California. MMWR Morb Mortal Wkly Rep [Internet]. 1981 [acesso 10 fev 2021];30(25):305-8. Disponível: https://bit.ly/33LZ89F

3. Barré-Sinoussi F, Chermann JC, Rey F, Nugeyre MT, Chamaret S, Gruest J et al. Isolation of a T-lymphotropic retrovirus from a patient at risk for acquired immune deficiency syndrome (AIDS). Science [Internet]. 1983 [acesso 10 fev 2020];220(4599):868-71. DOI: 10.1126/science.6189183

4. Santos LAC, Moraes C, Coelho VSP. Os anos 80: a politização do sangue. Physis [Internet]. 1992 [acesso 10 fev 2020];2(1):107-49. DOI: 10.1590/S0103-73311992000100005

5. Basílio FPS. Evolução das políticas de hemoterapia no Brasil: o sistema público de hemoterapia do Ceará [tese]. Fortaleza: Universidade Federal do Ceará; 2002.

6. Brasil. Senado Federal. Lei $\mathrm{n}^{\circ}$ 7.649, de 25 de janeiro de 1988. Estabelece a obrigatoriedade do cadastramento dos doadores de sangue bem como a realização de exames laboratoriais no sangue coletado, visando a prevenir a propagação de doenças, e dá outras providências. Diário Oficial da União [Internet]. Brasília, 27 jan 1988 [acesso 10 fev 2021]. Disponível: https://bit.ly/2RreDRD

7. Brasil. Constituição da República Federativa do Brasil de 1988. Diário Oficial da União [Internet]. Brasília, 5 out 1988 [acesso 10 fev 2021]. Disponível: https://bit.ly/2yjVK9X

8. Brasil. Lei $n^{\circ} 10.205$, de 21 de março de 2001. Regulamenta o $\S 4^{\circ}$ do art. 199 da Constituição Federal, relativo à coleta, processamento, estocagem, distribuição e aplicação do sangue, seus componentes e derivados, estabelece o ordenamento institucional indispensável à execução adequada dessas atividades, e dá outras providências. Diário Oficial da União [Internet]. Brasília, 21 mar 2001 [acesso 10 fev 2021 ]. Disponível: https://bit.ly/2SXjOJB

9. Brasil. Portaria de Consolidação $n^{\circ} 5$, de 28 de setembro de 2017 . Consolidação das normas sobre as ações e os serviços de saúde do Sistema Único de Saúde. Diário Oficial da União [Internet]. Brasília, 29 set 2017 [acesso 10 fev 2021]. Disponível: https://bit.ly/3wfPrMV

10. Agência Nacional de Vigilância Sanitária. Resolução - RDC n 34, de 11 de junho de 2014. Dispõe sobre as boas práticas no ciclo do sangue. Diário Oficial da União [Internet]. Brasília, 16 jun 2014 [acesso 10 fev 2021]. Disponível: https://bit.ly/2S044VO

11. Salvadori M, Hahn GV. Confidencialidade médica no cuidado ao paciente com HIV/aids. Rev. bioét. (Impr.). [Internet]. 2019 [acesso $10 \mathrm{fev}$ 2021];27(1):153-63. DOI: 10.1590/1983-80422019271298

12. Arruda ABL, Gomes FVBAF, Carneiro TRM, Moreira LM, Menezes FF, Souza LF et al. Importância do voto de autoexclusão na triagem dos doadores de sangue. Braz J Health Rev [Internet]. 2019 [acesso 10 fev 2021];2(6):5091-107. DOI: 10.34119/bjhrv2n6-017

13. Feil GS. Comunicação: condição ou impossibilidade humana? Galaxia [Internet]. 2013 [acesso 25 fev 2021];26:48-59. Disponível: https://bit.ly/33PeWbK 
14. Sampaio SS, Rodrigues FW. Ética e sigilo profissional. Serv Soc Soc [Internet]. 2014 [acesso 10 fev 2020];117:84-93. DOI: 10.1590/S0101-66282014000100006

15. Juramento de Hipócrates. Conselho Regional de Medicina do Estado de São Paulo [Internet]. São Paulo; 2001 [acesso 10 fev 2020]. Disponível: https://bit.ly/3bH1VEr

16. Conselho Federal de Medicina. Resolução $n^{\circ} 2.217$, de 27 de setembro de 2018. Aprova o Código de Ética Médica. Diário Oficial da União [Internet]. Brasília, nº 211, p. 179, 1 nov 2018 [acesso 10 fev 2021]. Disponível: https://bit.ly/33R6lj8

17. Conselho Regional de Medicina do Rio de Janeiro. Parecer CREMERJ N. 16/92 [Internet]. 1992 [acesso 16 maio 2021]. Disponível: https://bit.ly/3fpTgYP

18. Zanco G, Gonçalves ME, Bonamigo EL. Implicações do sigilo médico em caso de HIV positivo. Anais de Medicina [Internet]. 2018 [acesso 10 fev 2021];1:61-2. Disponível: https://bit.ly/3hvRFDF

19. Associação Brasileira de Normas Técnicas. ABNT NBR ISSO/IEC 17799:2005. São Paulo: ABNT; 2005.

20. Penitenciaria Apostólica reitera inviolabilidade do sigilo sacramental. Vatican News [Internet]. Sacramentos; 1 jul 2019 [acesso 10 fev 2021]. Disponível: https://bit.ly/3buLCeT

21. Assembleia Legislativa do Estado de São Paulo Lei no 10.241, de 17 de março de 1999. Dispõe sobre os Direitos dos usuários dos serviços e das ações de saúde no Estado. Diário Oficial do Estado de São Paulo [Internet]. 18 mar 1999 [acesso 10 fev 2021]. Disponível: https://bit.ly/3tPfskp

22. Agência Nacional de Vigilância Sanitária. Manual técnico de hemovigilância [Internet]. Brasília: Ministério da Saúde; 2003 [acesso 17 fev 2021]. Disponível: https://bit.ly/3uSW8UO

23. Ferreira O. Estudo de doadores de sangue com sorologia reagente para hepatites B e C, HIV e sífilis no hemocentro de Ribeirão Preto [tese]. São Paulo: Universidade de São Paulo; 2007.

Newton Key Hokama - Doutor - newton.hokama@unesp.br

(D) 0000-0001-7555-7215

Pedro Bonequini Junior - Mestre - pedro.bonequini@unesp.br

(iD) 0000-0001-9228-1337

Paula de Oliveira Montandon Hokama - Doutora - paula.hokama@unesp.br

(D) $0000-0003-3474-4422$

Correspondência

Newton Key Hokama - Avenida Professor Mário Rubens Guimarães Montenegro, s/n, Campus Universitário de Rubião Junior CEP 18618-687. Botucatu/SP, Brasil.

Participação dos autores

Newton Key Hokama foi o idealizador da pesquisa e principal redator do artigo. Pedro Bonequini Junior colaborou com a discussão sobre o estudo e com a redação do texto, principalmente com relação à prática hemoterápica. Paula de Oliveira Montandon Hokama também participou da discussão e revisou o texto final.

Recebido: 12.3 .2020

Revisado: $\quad 4.5 .2021$

Aprovado: 5.5 .2021 